\title{
Avaliação sustentável para instalação de aterro sanitário em uma cidade da Amazônia oriental
}

A gestão do lixo produzido pelos centros urbanos tem sido um desafio para o Brasil. Nos últimos 20 anos, este assunto vem sendo o alvo de muitas medidas educativas, leis e diretrizes que buscam minimizar os problemas causados pela má gestão desses resíduos. Neste trabalho foi proposta uma metodologia, utilizando dados do sistema de informações geográficas e do sensoriamento remoto, com o objetivo de avaliar o território onde está localizado a cidade de Castanhal e selecionar a área que mais se ajuste as atuais normas federais de gestão do lixo urbano e de sustentabilidade. Observou-se que além da cidade manter um lixão a céu aberto, sem nenhum tratamento, o local é inadequado por estar próxima de rios, região de alagamento e casas. Em seguida, usando dos mesmos critérios que tornam a área do atual lixão imprópria, foi selecionado através da análise de terreno (relevo, hidrografia e proximidade do centro urbano) o local ideal para a instalação do projeto de aterro sanitário. Sendo este um trabalho preliminar com o objetivo de apresentar uma ferramenta simples e de baixo custo e que pode ser essencial para a tomada de decisão dos responsáveis pela gestão do lixo urbano da cidade de Castanhal.

Palavras-chave: Amazônia; Sensoriamento remoto; Gestão de resíduos sólidos.

\section{Sustainable evaluation for sanitary landfill installation in an eastern Amazonian city}

The management of waste produced by urban areas has been a challenge for Brazil. In the last 20 years, this matter has been the subject of many measure educational, laws and guidelines that seek to minimize the problems caused by the mismanagement of waste. In this work, a method was proposed, using data from a geographic information system and remote sensing with the aim of evaluating the area where is located the city of Castanhal and select the area that fits most current federal standards for waste management urban. It was observed that, despite the city maintain an open-air dump, without any treatment, the site is unsuitable of for being close to rivers and region of waterlogged and homes. Then, using the same criteria that make the area unsuitable for the current landfill, was selected through analysis of land (topography, hydrography and proximity to the city center) was selected the ideal local for installation of the landfill project site. Since this is a preliminary work, the objective is provide a simple and inexpensive tool which can be essential to the decision making of those responsible for the management of municipal waste in the city of Castanhal.

Keywords: Amazon; Remote sensing; Management of solid waste.

Topic: Desenvolvimento, Sustentabilidade e Meio Ambiente

Reviewed anonymously in the process of blind peer
Received: 04/05/2020

Approved: 29/06/2020
Giordani Rafael Conceição Sodré (ic

Universidade Federal do Pará, Brasil

http://lattes.cnpq.br/0513329362156835

http://orcid.org/0000-0002-8918-973X

giordani@ufpa.br

Stephanie Jael Negrão de Freitas (iD)

Universidade Federal do Pará, Brasil

http://lattes.cnpq.br/1432769722634758

http://orcid.org/0000-0001-9917-5342

negro.stephanie@gmail.com

Jeferson Botelho Rodrigues (ic)

Universidade Vale do Rio Verde, Brasil

http://lattes.cnpq.br/9702846379230129

http://orcid.org/0000-0001-6371-7912

botelhojef@outlook.com

\author{
Tassio Koiti Igawa (ic \\ Universidade Federal do Pará, Brasil \\ http://lattes.cnpq.br/3470162533151652 \\ http://orcid.org/0000-0001-9974-0380 \\ tassio.igawa@gmail.com \\ Islia Lima de Sousa Amorim (D) \\ Universidade Federal do Pará, Brasil \\ http://lattes.cnpq.br/2161191307542899 \\ http://orcid.org/0000-0001-6629-5794 \\ islia.amorimeng@gmail.com \\ Ana Carla Leite Carvalho Cabral \\ Universidade da Amazônia, Brasil \\ http://lattes.cnpq.br/6538382004505294 \\ http://orcid.org/0000-0002-1735-1320 \\ calincarvalho@gmail.com
}

Referencing this:

SODRÉ, G. R. C.; FREITAS, S. J. N.; RODRIGUES, J. B.; IGAWA, T. K.; AMORIM, I. L. S.; CABRAL, A. C. L.. Avaliação sustentável para instalação de aterro sanitário em uma cidade da Amazônia oriental. Nature and Conservation, v.13, n.3, p.112-121, 2020. DOI: http://doi.org/10.6008/CBPC2318-2881.2020.003.0011 


\section{INTRODUÇÃO}

A cidade de Castanhal é um dos mais importantes núcleos urbanos da região nordeste do estado do Pará, sua localização geográfica favorece um grande fluxo de pessoas em seu território, uma vez que a cidade é principal rota de entrada e saída de todo tipo de produto importando e exportado, via terrestre, que saí da capital Belém ou da região do Salgado, como é conhecido o litoral paraense. Considerada uma cidade de médio porte, Castanhal possui uma área de 1.029,191 km² e uma população, segundo o Instituto Brasileiro de Geografia e Estatística (IBGE), estimado em 186.895 mil pessoas. Possui um Produto Interno Bruto (PIB) per capita de $\mathrm{R} \$ 9.118,19$.

Em Castanhal, assim como outras cidades brasileiras do seu porte, a população tem aumentado rapidamente. Segundo o IBGE no ano de 1991 a população da cidade de Castanhal era de 102.071 mil habitantes, dez anos depois a população saltou para 134.496 mil e no ano de 2014 a estimativa da população local é de 186.895 mil habitantes, podendo ultrapassar os 200 mil a qualquer momento. Ou seja, em pouco mais de 24 anos a população de Castanhal aumentou em 84.824 mil pessoas, um acréscimo de 54,6 \% na população.

Esses números se refletem na grande quantidade de moradias irregulares, invasões, e principalmente da grande quantidade de lixo produzido por pela população que em muitos casos dá um destino indevido ao mesmo. Destino esse que também não é tão diferente do procurado pelo governo municipal, que matem um lixão a céu aberto a mais de 10 anos, onde despeja sem nenhum tipo de tratamento, todo o resíduo e entulho coletado na região urbana de Castanhal. Contudo, a lei federal da Política Nacional de Resíduos Sólidos de 02 de agosto de 2010, determinou a extinção de todos os lixões do Brasil, dando um prazo de quatro anos para todos os municípios se adequarem as novas regras.

A cidade de Castanhal ficou entre os municípios que não apresentaram um plano de combate ao despejo irregular de seu lixo, alegando não possuir recursos financeiros suficientes para execução do projeto, sendo que agora, o governo municipal recebeu um novo prazo, para que um plano emergencial para a implantação de um aterro sanitário seja criado, e o despejo a céu aberto encerrado. A pena para o descumprimento do novo prazo pode chegar aos $\mathrm{R} \$ 50$ milhões de multa por dia.

O Aterro Sanitário é um equipamento projetado para receber e tratar o lixo produzido pelos habitantes de uma cidade, com base em estudos de engenharia, para reduzir ao máximo os impactos causados ao meio ambiente. Atualmente é uma das técnicas mais seguras e de mais baixo custo. A aplicação de múltiplos critérios para escolha do local final de armazenamento de resíduos sólidos é evidenciada em estudos na literatura. No artigo de Campo de Cazarini (2010) são enumerados os seguintes autores e processos:

Lahdelma et al. (2002) faz análise de multicritério para escolher a localização de um aterro sanitário na Finlândia. A tomada de decisão estabeleceu como critérios: proximidade com águas subterrâneas, proximidade com águas de superfície, efeitos no habitat, proximidade da população para odores emitidos, paisagismo do local, custo com transporte, mudança futura no valor do terreno, crescimento populacional. 
Norese (2006) estudou a localização de incineradores e de aterro para o destino final de resíduos sólidos. Entre os critérios para tomada de decisão estão: acessibilidade, população, impacto no paisagismo, proximidade com água subterrânea, proteção do habitat natural, potencial agrícola da região. Lima (2005) fez estudo da localização de aterro sanitário utilizando lógica nebulosa com múltiplos critérios que foram: proximidade de cursos d'água, permeabilidade do solo, distância do lençol freático, proximidade de núcleos residenciais, distância de aeroportos.

Calijuri et al. (2002) aplicaram lógica fuzzy e análise multicritério para seleção de áreas de implantação de aterros sanitários, para isso utilizou condicionantes legais, operacionais, ambientais e socioeconômicos. Entre as restrições ambientais consideradas para localização estão: distância mínima de 200 metros de coleção hídrica ou curso d’água; distância mínima de 200 metros do sistema viário; distância mínima de 200 metros de falhas geológica.

Santos et al. (2007) aplicaram vários critérios para localizar áreas propícias para implantação de aterros sanitários na região oeste do Estado do Rio Grande do Sul. Os aspectos propostos foram: tamanho da área e tempo de vida útil do aterro sanitário (no mínimo, 20 anos), proximidade da zona de coleta (no máximo a $20 \mathrm{~km}$ de distância), via de acesso em boas condições, distância de mais de 1,5km de aeroportos, afastamento mínimo de $2 \mathrm{~km}$ de zonas residenciais, distância de mais de $200 \mathrm{~m}$ de nascentes, corpos d'água e rios, posicionamento adequado em relação aos ventos dominantes e concordância com as leis ambientais.

Lozano (2006) faz avaliação de locais para barragens de rejeitos utilizando o método de análise hierárquica considerando os seguintes critérios: impactos a jusante por possível ruptura da barragem, transporte de rejeitos ao local, implantação da barragem. $\mathrm{O}$ autor analisou o impacto destes três grupos de critérios considerando o conjunto de subcritérios relacionados a cada grupo. Os subcritérios estudados foram: fauna, ocupação humana, água e flora.

O Centro de Estudos e Pesquisas Urbanas - CPU/IBAM (1998) levanta vários aspetos para definição do local como: propriedade (se está disponível para compra), tamanho da área (a utilidade deve ser de, no mínimo, 10 anos), localização da área (não deve estar localizada a mais de $15 \mathrm{~km}$ da zona de coleta e devem estar afastada no mínimo $2 \mathrm{~km}$ de zonas residenciais), apresentar vias de acesso em boas condições, estar afastado de aeroportos, localizar longe de nascentes e cursos d'água, apresentar redes de energia, telefone e outros serviços. Devem-se observar também características topográficas, tipos de solo e águas subterrâneas.

A má gestão do lixo e sua deposição sem tratamento sobre o meio ambiente acarreta diversos problemas, como o aparecimento do Chorume, que segundo Santos et al. (2007), é uma substância gerada nos processos de degradação dos resíduos sólidos urbanos em locais de disposição de resíduos sólidos urbanos. Outra importante característica do chorume são as altas cargas de contaminantes orgânicos e inorgânicos, representando assim uma fonte de poluição significativa, seja em grandes centros ou pequenos aglomerados urbanos.

A percolação do chorume resultante de depósitos de resíduos no solo é caracterizada como difusa, não se podendo determinar com exatidão o grau de contaminação gerado. Ressalte-se que as águas 
superficiais e subterrâneas se encontram interligadas na maioria dos casos; em algumas situações, os mananciais de superfície proporcionam a recarga dos reservatórios subterrâneos, enquanto, em outras, as águas do subsolo descarregam em recursos hídricos superficiais.

Em detrimento a esta demanda várias técnicas vêm sendo utilizadas como contribuição à questão de recuperação de áreas degradadas, entre elas as técnicas de geoprocessamento que, aplicadas aos dados disponíveis, estes embasados em experiências anteriores e na observação da realidade, permitem a análise e a obtenção de diversos planos de informação homogêneos para locais distintos. Torna-se oportuno o desenvolvimento de uma ferramenta de análise que permita a categorização dos locais, com a proposição de medidas globais para categorias semelhantes, que unifiquem o diálogo e facilitem a tarefa dos administradores. Com esta perspectiva, este estudo propõe o uso de técnicas de sensoriamento remoto, tecnicamente e economicamente acessíveis e viáveis, para a seleção da melhor localidade dentro do município de Castanhal, no esta do Pará na região Amazônica, para a implantação do projeto de aterro sanitário.

\section{MATERIAIS E MÉTODOS}

\section{Área de estudo}

A cidade de Castanhal (Figura 1) está localizada a região nordeste do estado do Pará, a $68 \mathrm{~km}$ da capital Belém e a $2.078 \mathrm{~km}$ de Brasília. Localiza-se a uma latitude $01^{\circ} 17^{\prime} 49^{\prime \prime}$ Sul e a uma longitude $47^{\circ} 55^{\prime}$ 19" Oeste, estando a uma altitude de 41 metros acima do nível médio do mar.

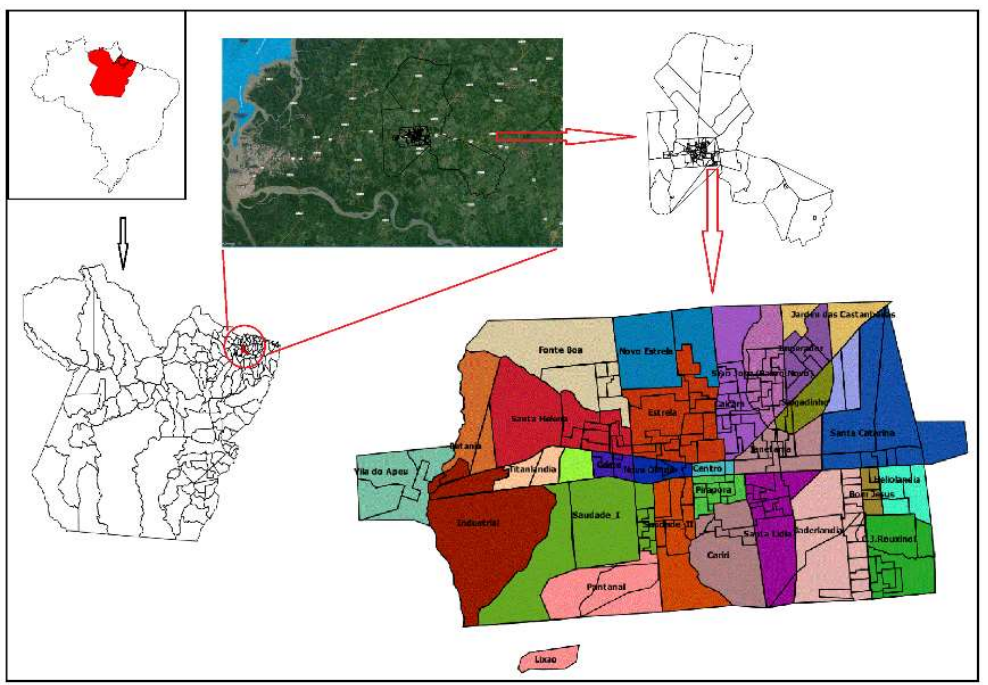

Figura 1: Localização geográfica da cidade e respectivos bairros.

\section{Processamento de Dados}

Os dados utilizados para a realização deste estudo foram: imagens de satélites obtidas por meio do software Google Earth, dados relevo e topografia da EMBRAPA e IBGE, dados de precipitação e hidrografia da Agência Nacional de Águas (ANA), informações sobre a gestão de resíduos sólidos do município de Castanhal, disponibilizados pelo IBGE e MMA (Ministério do Meio Ambiente).

A metodologia empregada baseou-se nas normas técnicas de implantação de um aterro sanitário 
disponibilizado pelo MMA em seu 'Manual de instalação de um aterro sanitário', disponibilizado no endereço eletrônico ${ }^{1}$, no qual determinar diretrizes técnicas e ambientais para o emprego do mesmo.

A partir das normas técnicas contidas no manual acima mencionado, que determinam as condições de altura do terreno, distância de rios, lagos e casas dentre outros, foi empregado o modelo de elevação de terreno da EMBRAPA, por meio do qual foram selecionadas as áreas que se adequavam a essas características. Em seguida, por meio da localização dos rios e lagos que cortam a cidade, observados através dos dados da ANA, foram determinadas a zonas de várzea e alagados.

Com dos dados de precipitação foram reproduzidos a climatologia local, bem como os meses mais chuvosos e secos, e como esse parâmetro pode interferir no agravamento dos impactos ambientais provocados pelo lixão. Por fim, utilizando as imagens de satélite, foi observado as condições do atual lixão e feita a visualização da área selecionada para a implantação do projeto do aterro sanitário da cidade de Castanhal.

Para o procedimento de projeção, edição e adequação dos dados de satélite e arquivos shape, foi utilizado o software de sistema de informação geográfica Quantum GIS por ser um software de geoprocessamento com licença gratuita e bastante utilizado para pesquisa.

\section{RESULTADOS E DISCUSSÃO}

A produção de lixo urbano na cidade de Castanhal atingiu elevados níveis nos últimos dez anos, a secretaria de saúde e meio ambiente da cidade estima que, nos últimos sete anos, a produção de lixo urbano saltou de 110 para 200 toneladas diárias, ou seja, houve um aumento de quase $100 \%$ da produção de resíduos. Essa elevação da produção de lixo está relacionada diretamente com o rápido aumento da população da cidade, como já mostrado. Contudo, o governo municipal não acompanhou este crescimento de forma estratégica e ambientalmente correta, continuando assim o despejo do lixo de forma irregular.

Situação que saiu do controle no ano de 2014, quando foi preciso uma intervenção do Ministério Público Estadual, pois a situação do lixão já estava caótica. Com o local sobrecarregado de resíduos e a prefeitura sem espaço para depositar as coletas diárias, passou a espalhá-los pelos acessos e ruas que ligam o lixão a cidade de Castanhal (Figura 2). O que gerou alguns protestos dos moradores do bairro do Pantanal e da Agrovila Boa Vista onde o lixão está localizado.

Moradores do bairro Pantanal e da agrovila Boa Vista em Castanhal, no nordeste do estado, reclamam do despejo irregular de lixo na entrada do aterro sanitário, que está cada vez mais próximo das casas localizadas na zona rural do município. A área onde o lixo é depositado está sendo tomada pelo lixo, que se acumula nas estradas que dão acesso à agrovila, dificultando a vida dos moradores. Além de obstruir as estradas com entulho e provocar mau cheiro, o lixão estaria contaminando os igarapés e nascentes de água da região, que ficam a poucos metros do aterro.

Esta forma de despejo pode acarretar diversos riscos à saúde das pessoas que moram próximas quanto para o meio ambiente. Segundo um artigo no dia 18 de setembro de 2014 publicado pela Universidade de São Paulo (USP), o lixo depositado em lixões a céu aberto ou em terrenos baldios atrai ratos,

\footnotetext{
${ }^{1}$ http://www.mma.gov.br/
} 
baratas, moscas, mosquitos, formigas e escorpiões, entre outros, podendo transmitir doenças como diarreias infecciosas, parasitoses, amebíase etc. Pode ainda permitir o desenvolvimento de larvas de mosquitos vetores de doenças como a dengue e a leishmaniose.



Figura 2: Localização geográfica da região de despejo do lixo em Castanhal. As setas indicam o aumento das áreas de despejo desordenado.

\section{Regime Pluviométrico e consequência sobre o Lixão}

Castanhal possui um clima chuvoso bastante intenso, com dois períodos bem definidos, o chuvoso e seco. Segundo a Agência Nacional de Águas (ANA), Castanhal apresenta anualmente um volume acumulado médio de precipitação de $2.500 \mathrm{~mm}$, que pode variam entre $1500 \mathrm{~mm}$, em anos mais secos ou atingir 4500 $\mathrm{mm}$, em anos mais chuvosos.

Os dados pluviométricos climatológicos de Castanhal mostram que eventos de precipitação acima de $100 \mathrm{~mm}$, apresentam $50 \%$ ou mais de chances de ocorrerem durante o período de nove meses (dezembro a agosto) (Figura 4). Entretanto, no período chuvoso, que se estende de janeiro a Abril, os volumes podem chegar aos $400 \mathrm{~mm}$, conforme observado no mês de Março, caracterizando o mês de maior perigo para a contaminação ambiental dos rios, lagos e lençol freático localizado nas proximidades do lixão.

Segundo Serafim et al. (2003), por apresentar substâncias altamente solúveis, o chorume pode contaminar as águas do subsolo nas proximidades do aterro. A presença do chorume em águas subterrâneas pode ter consequências extremante sérias para o meio ambiente e para a saúde pública, por apresentar compostos altamente tóxicos. Devido a movimentação dos lençóis o chorume pode se dispensar e atingir poços artesianos (FONSECA, 2001; NÓBREGA et al., 2008).

Em relação às atuais discussões sobre mudanças climáticas em todo o mundo, onde a redução da precipitação, e o aumento de eventos climáticos severos caracterizam-se como uma realidade cada vez mais notória, os dados pluviométricos climatológicos de Castanhal mostram que os dias de chuva têm apresentado redução nos últimos trinta anos, porém o número de eventos de precipitação acima dos $100 \mathrm{~mm}$ passou a ser mais frequente, ou seja, o número de dias com chuva sobre a cidade de Castanhal diminuiu, quando comparado aos últimos 30 anos, porém a intensidade desses eventos se intensificou (Figura 5). 


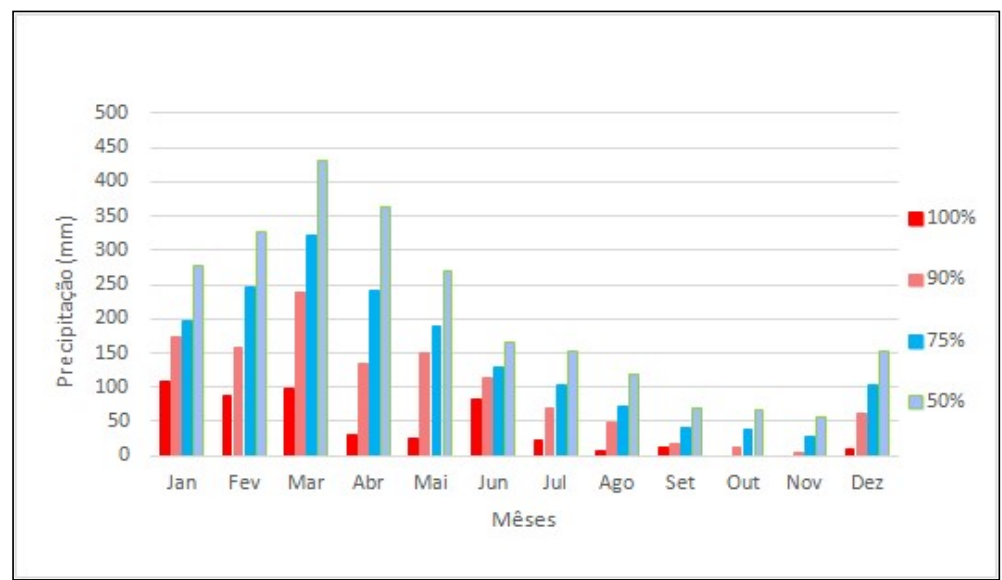

Figura 4: Frequência mensal de eventos extremos de precipitação.

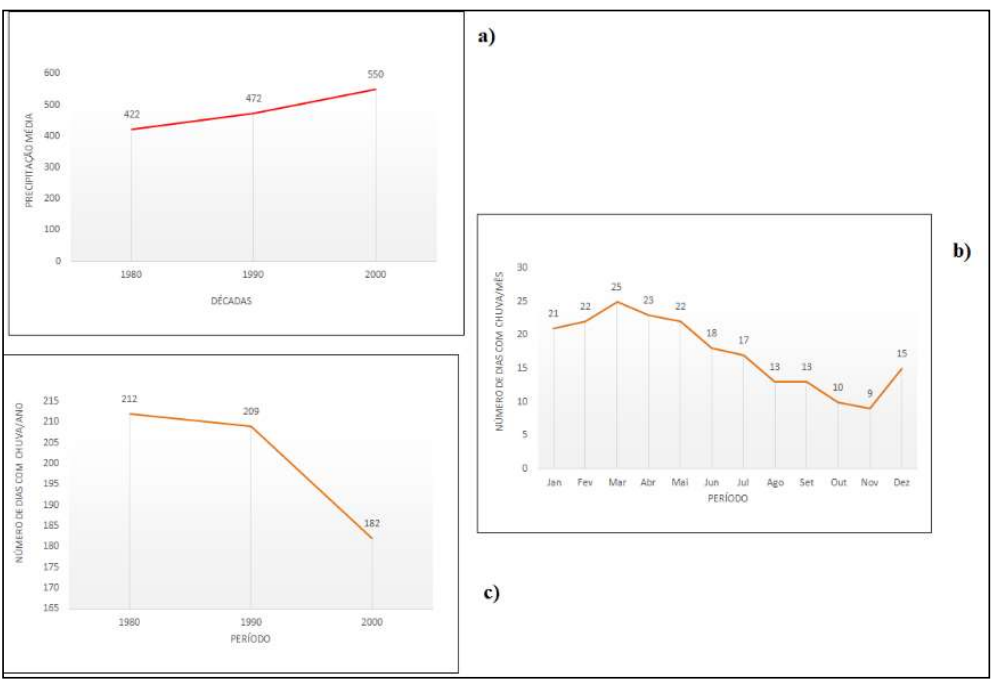

Figura 5: Média mensal do acumulado pluviométricos dos eventos de precipitação máxima diária das últimas três décadas a), Número médio climatológico de dias de chuva por mês b) e c) frequência de dias com chuvas das últimas três décadas (1980, 1990 e 2000).

O alto volume anual de precipitação (Figura 3), aproximadamente 4000 mm (10,9 mm/dia), e capaz de lavar o solo e contribuir para a infiltração do líquido percolado, conhecido vulgarmente como chorume. Segundo Serafim et al. (2003), o impacto produzido pelo chorume sobre o meio ambiente está diretamente relacionado com a sua fase de decomposição. O chorume de aterro novo, quando recebe boa quantidade de águas pluviais é caracterizado pelo $\mathrm{pH}$ ácido, alta Demanda Bioquímica de Oxigênio $\left(\mathrm{DBO}_{5}\right)$, alto valor de Demanda Química de Oxigênio (DQO) e diversos compostos potencialmente tóxicos (SEFARIM et al., 2003).

Além dos impactos ambientais, existem os riscos da proliferação dos vetores de doenças, como os insetos. Segundo Dias et al. (2011), que estudando a influência climática sazonal uma população de moscas em um lixão, observou que a alta temperatura do ar combinada com elevadas taxas de umidade (devido a precipitação), provocam um aumento significativo desses insetos. Segundo o IBGE (2002), existem dois tipos de vetores de doenças que podem surgir a partir de áreas com deposito irregular de resíduos sólidos: os macrovetores (cachorros, gatos, ratos, urubus, pombos e outros), e os microvetores (moscas, mosquitos, bactérias, fungos e outros). 


\section{Seleção da melhor área para a implantação de um aterro sanitário}

Todas as consequências citadas acima mostram a importância de um destino adequado para os resíduos, produzidos pela população. E o aterro sanitário é no momento a melhor opção para que o lixo produzido pare de causar danos à saúde humana e ao meio ambiente. Segundo Mazzer et al. (2004) o aterro sanitário é uma forma de disposição de resíduos no solo que, fundamentada em critérios de engenharia e normas operacionais específicas, garante um confinamento seguro em termos de poluição ambiental.

A área a receber o aterro sanitário precisa possuir elevação suficiente para que o lençol freático esteja protegido, caso ocorra o vazamento do chorume produzido pela disposição do mesmo. Contudo não existe uma medida exata do tamanho ou profundidade da célula, ela varia de acordo com a quantidade de lixo a ser empregada, porém adote-se para efeitos de cálculos, células que vão de 2 a 6 metros de profundidade.

A partir deste critério, analisamos a área do atual lixão da cidade de Castanhal, podemos constatar algumas irregularidades. Observando a Figura 6, que apresenta a cidade de Castanhal em relevo e hidrografia onde as cores próximas do laranja representam as regiões de rios e zonas de alagados, e a cor mais próxima do marrom indica os locais mais altos e propícios para a implantação do aterro sanitário.

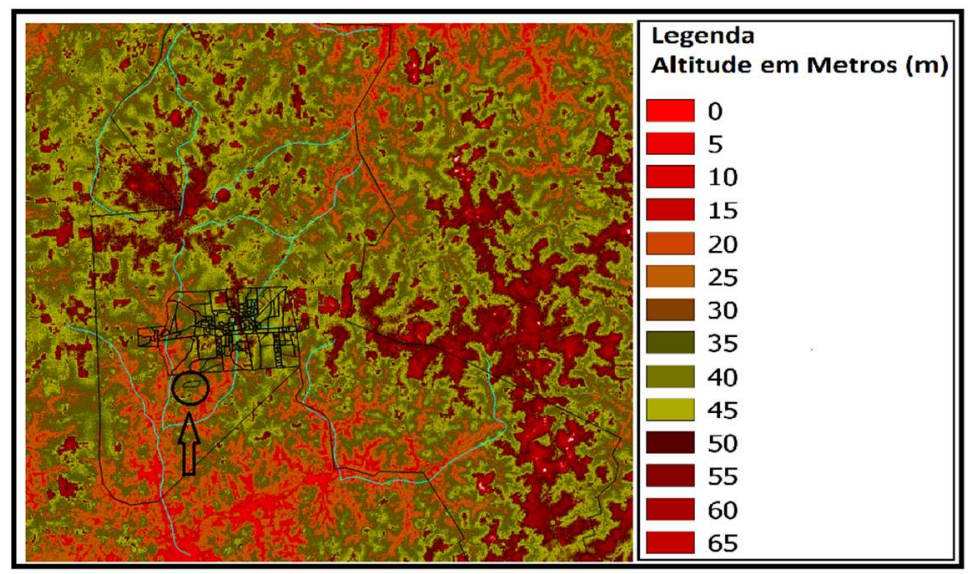

Figura 6: Relevo e hidrografia de Castanhal. A seta indica a localização do atual lixão.

Nota-se que o lixão está em uma área relativamente baixa, conforme destacado pela seta, próxima de uma região de alagado, e dessa forma, elevando as possibilidades de poluição tanto das águas superficiais como as do lençol freático, que nesse local está mais próximo da superfície. Apenas o fator de proximidade de uma região de alagado e rio, já é suficiente para que essa área seja considerada como fora dos padrões estabelecidos como fundamentais para a construção de um aterro sanitário.

Ainda na figura 06 percebe-se que levando em conta a localização dos rios e a altitude do terreno e proximidade do centro urbano da cidade de Castanhal, o local mais indicado para a construção de um aterro sanitário seria a região leste da cidade, como indicado na imagem na Figura 7, que mostra o local que apresentou a melhor adequação do relevo, hidrografia e proximidade do centro urbano. 


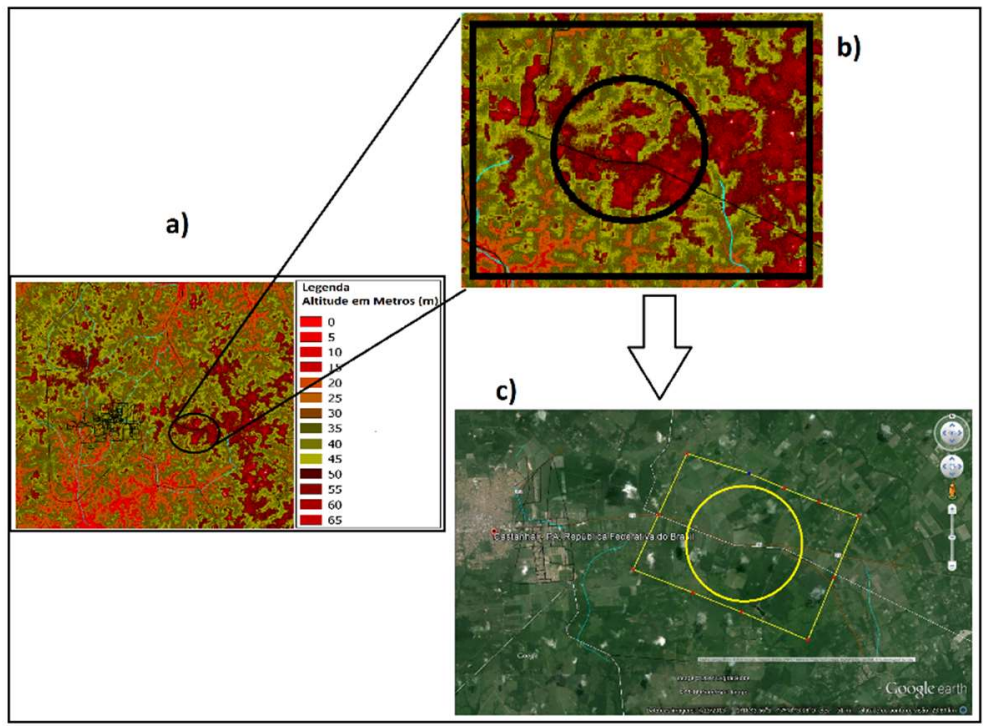

Figura 7: Melhor local para um aterro sanitário, onde a) Cidade de Castanhal em relevo; b) Destaque da localidade com relevo mais indicado para um aterro sanitário; c) Imagem do satélite destacando o modo de ocupação da área selecionada.

A região selecionada compreende uma área de mais ou menos $33 \mathrm{~km}^{2}$, formada principalmente por fazendas, o que é mais viável em termos de indenizarão para a liberação do local pelo proprietário para que o aterro possa ser instalado. Com uma área desta proporção é possível instalar e manter vários pontos de aterro sanitário, o qual possui vida média útil de 6 a 10 anos.

\section{CONCLUSÕES}

A atual localização do lixão da cidade de Castanhal desrespeita as normas ambientais vigentes, tornando o município passível das sanções econômicas, aplicáveis pelo governo federal através do MMA. O sensoriamento remoto associado a climatologia constituem técnicas extremante úteis para a tomada de decisões governamentais relacionadas ao planejamento ambiental e urbano, entretanto é necessário que as autoridades responsáveis se ajustem as normas ambientais vigentes, permitindo que a maior parte dos recursos públicos sejam empregados de forma correta, na criação e manutenção do aterro sanitário.

\section{REFERÊNCIAS}

CALIJURI, M. L.; MELO, A. L. D.; LORENTZ, J. F.. Identificação de áreas para implantação de aterros sanitários com uso de análise estratégica de decisão. Informática pública, v.4, n.2, p.231-250, 2002.

CPU/IBAM. Centro de Pesquisas Urbanas do Instituto Brasileiro de Administração Municipal. $\mathbf{O}$ que é preciso saber sobre limpeza urbana: tratamento e disposição final do lixo. Ministério da Ação Social, 1998.

DIAS, L. S.; ALEIXO, N. C. R.; GUIMARÃES, R. B.. Influência da sazonalidade climática na ocorrência de moscas no lixão urbano de presidente prudente, São Paulo. Fórum Ambiental da Alta Paulista, v.7, n.12, 2011.

FONSECA, F.. Iniciação ao estudo dos resíduos sólidos e da limpeza urbana. JRC, 2001.
IBGE. Instituto Brasileiro de Geografia e Estatística. Pesquisa nacional de saneamento básico. Rio de Janeiro: IBGE, 2002.

LAHDELMA, R.; SALMINEM, P.; HOKKANEN, J.. Locating a waste treatment facility by usings to chastic multicriteri a acceptability analysi swith ordinal criteria. Europe na journal of operational research, v.142, p.345-356, 2002.

LIMA, F. R. N.. Localização de aterro sanitário utilizando lógica nebulosa. Dissertação (Mestrado em engenharia civil) - Universidade Federal do Rio de Janeiro, Rio de Janeiro, 2005.

LOZANO, F. A. E.. Seleção de áreas de locais para barragem de rejeitos usando método de análise hierárquica. Dissertação (Mestrado em engenharia civil) - Universidade de São Paulo, São Paulo, 2006. 
MAZZER, C.; CAVALCANTE, O. A.. Introdução à gestão ambiental de resíduos. Infarma, v.16, n.11-12, 2004.

NÓBREGA, C. C.; SOUZA, I. M. F.; ATHAYDE, G. B.; GADELHA, C. L. M.. Impacto de um lixão desativado na qualidade das águas subterrâneas locais. In: SIMPÓSIO IBEROAMERICANO DE INGENIERÍA DE RESÍDUOS, 1. Anais. 2008.

NORESE, M. F.. Electre iii as a support for participatory decision-making on the localization of waste-treatment plants. Land Use Policy, v.23, p.76-85, 2006.
SANTOS, J. S. D.; GIRARDI, A. G.. Utilização de geoprocessamento para localização de áreas para aterro sanitário no município de Alegrete-RS. In: SIMPÓSIO BRASILEIRO DE SENSORIAMENTO REMOTO, 13. Anais. Florianópolis, 2007. p.21- 26

SERAFIM, A. C.; GUSSAKOV, K. C.; SILVA, F.; CONEGLIAN, C. M. R.; BRITO, N. N.; SOBRINHO, G. D.; TONSO, S.; PELEGRINI, R.. Chorume, impactos ambientais e possibilidades de tratamento. In: FÓRUM DE ESTUDOS CONTÁBEIS. Anais. Rio Claro: Faculdades Integradas Claretianas, 2003.

A CBPC - Companhia Brasileira de Produção Científica (CNPJ: 11.221.422/0001-03) detém os direitos materiais desta publicação. Os direitos referem-se à publicação do trabalho em qualquer parte do mundo, incluindo os direitos às renovações, expansões e disseminações da contribuição, bem como outros direitos subsidiários. Todos os trabalhos publicados eletronicamente poderão posteriormente ser publicados em coletâneas impressas sob coordenação da Sustenere Publishing, da Companhia Brasileira de Produção Científica e seus parceiros autorizados. Os (as) autores (as) preservam os direitos autorais, mas não têm permissão para a publicação da contribuição em outro meio, impresso ou digital, em português ou em tradução. 